\title{
Effects of cadmium and lead on the growth and the activity of peroxidase and superoxide dismutase of blueberry plantlets in vitro
}

\author{
J.Z. CHEN*, L.P. ZHOU, C.Y. TIAN, F. YANG, and G.Z. WANG \\ School of Life Sciences, Huzhou University, Huzhou 313000, P.R. China
}

\begin{abstract}
To study the effects of cadmium and lead on the growth of blueberry (Vaccinium ashei Reade) plantlets in vitro and on the activity of peroxidase (POD) and superoxide dismutase (SOD) of blueberry shoots, $\mathrm{Cd}^{2+}$ and $\mathrm{Pb}^{2+}$ were added separately to a cultivation medium. The results show that $0.01 \mathrm{mM} \mathrm{Cd}^{2+}$ significantly inhibited the growth of blueberry shoots, and the height and fresh mass of the shoots were significantly lower than those of the control; $0.05 \mathrm{mM} \mathrm{Cd}^{2+}$ significantly inhibited the proliferation of the shoots; the inhibitory effect on the growth and proliferation of blueberry in vitro was enhanced with the increase of $\mathrm{Cd}^{2+}$ concentration. Also $\mathrm{Pb}^{2+}(0.10-1.00 \mathrm{mM})$ significantly decreased the proliferation of the shoots, but it did not decrease significantly the shoot height and fresh mass. After $20 \mathrm{~d}$ of $\mathrm{Cd}$ or Pb treatments, the POD and SOD activities of the shoots increased with the increase of their concentrations, and when the concentration was $1.00 \mathrm{mM}$, the POD and SOD activities were significantly higher than in the control; the effect of $\mathrm{Pb}^{2+}$ on POD and SOD activities was generally stronger than that of $\mathrm{Cd}^{2+}$. The upregulation of activities of antioxidative enzymes played an effective role in acclimatization to these stresses, especially to $\mathrm{Pb}$ stress.
\end{abstract}

Additional key words: antioxidants, heavy metals, Vaccinium ashei.

In recent years, due to the impact of human activities, a large number of heavy metals such as cadmium and lead have been released into the soil, resulting in the increasingly serious pollution in the soil (Chen et al. 2014). Cd and $\mathrm{Pb}$ in soil not only affect the yield and quality of plants, but also accumulate in animals and human bodies through the food chain, threatening their health (Xiao et al. 2015, Tóth et al. 2016). Therefore, the content of $\mathrm{Cd}$ and $\mathrm{Pb}$ in contaminated soil and the tolerance mechanisms of plants to $\mathrm{Cd}$ and $\mathrm{Pb}$ stress attract great attention.

Blueberries (Vaccinium spp.) are perennial berry fruit trees of Ericaceae family. Blueberry fruits are popular around the world due to their nutritional value and elevated content of bioactive phenolic compounds (Kalt et al. 2007, 2020). Although many species of blueberries are native to North America, several of them especially highbush ( V. corymbosum L.), lowbush ( $V$. angustifolium Ait.), and rabbiteye ( $V$. ashei Reade) blueberries are commercially cultivated in many countries in Europe, South America, Asia, Australia, and New Zealand (Strik 2005, Strik and Yarborough 2005). Soil is one of the main limiting factors that make it difficult to expand the cultivation scope of blueberry. Blueberry cultivation requires high soil quality; loose and acid soil rich in organic matter and with a low heavy metal content (Markus and Mcbratney 1996). However, there are few reports about the effect of heavy metal stress on the growth of blueberry.

In this paper, the effects of cadmium and lead stress on the growth and antioxidant enzyme activities in blueberry ( $V$. ashei cv. Garden blue) grown in vitro were studied, in order to provide scientific basis for promotion of blueberry growing area, as well as to give theoretical basis for revealing the tolerance mechanisms of plants to cadmium and lead.

The sterile shoots of blueberry were provided by the Plant Biotechnology Laboratory at Huzhou University. The shoots were multiplied on a woody plant medium (Lloyd and McCown 1980) with zeatin (1.5 $\mathrm{mg} \mathrm{dm}^{-3}$ ), $\operatorname{agar}\left(5 \mathrm{~g} \mathrm{dm}^{-3}\right)$, and sucrose $\left(20 \mathrm{~g} \mathrm{dm}^{-3}\right), \mathrm{pH}$ 5.2. Blueberry shoot cultures were kept at a temperature of $25 \pm 2{ }^{\circ} \mathrm{C}$, a 12-h photoperiod, and an irradiance at the culture level of $50 \mu \mathrm{mol} \mathrm{m} \mathrm{m}^{-2} \mathrm{~s}^{-1}$ provided by cool white fluorescent lamps. Stock solutions of $10 \mathrm{mM} \mathrm{Cd}^{2+}$ or $\mathrm{Pb}^{2+}$ were prepared using $\mathrm{Cd}\left(\mathrm{NO}_{3}\right)_{2} \cdot 4 \mathrm{H}_{2} \mathrm{O}$ and $\mathrm{Pb}\left(\mathrm{NO}_{3}\right)_{2}$, respectively. For cadmium

\footnotetext{
Submitted 26 May 2020, last revision 20 September 2020, accepted 2 October 2020.

Abbreviations: POD - peroxidase; SOD - superoxide dismutase.

Acknowledgments: This work was financially supported by the National Natural Science Foundation of China (No. 20977027) and the Zhejiang Provincial Natural Science Foundation of China (No. LY16C020003).

* Corresponding author; e-mail: jzchen@zjhu.edu.cn
} 
stress treatment $0.01,0.05,0.10,0.50$, and $1.00 \mathrm{mM} \mathrm{Cd}^{2+}$ were added to the above mentioned medium, and 0.01 , $0.05,0.10,0.50$, and $1.00 \mathrm{mM} \mathrm{Pb}^{2+}$ were added to medium for lead stress treatment; distilled water was used as the control, and all the final media were adjusted to $\mathrm{pH}$ 5.2. Each bottle with medium was inoculated with five sterile blueberry shoots and the shoot cultures were maintained in the same condition as mentioned above. After 10 and $20 \mathrm{~d}$ of culture, blueberry shoots were sampled triply for each treatment for enzyme assay. The height, fresh mass, and multiplication coefficient were examined after $75 \mathrm{~d}$ of culture.

Vaccinium shoots $(0.5 \mathrm{~g})$ were ground to a slurry with a mortar and pestle with $4 \mathrm{~cm}^{3}$ of phosphate buffer ( $\left.\mathrm{pH} 7.0\right)$ containing $1 \%(\mathrm{~m} / \mathrm{v})$ of polyvinylpyrrolidone (PVPP) under cooling condition (ice bath). The homogenates were centrifuged at $14000 \mathrm{~g}$ and $4{ }^{\circ} \mathrm{C}$ for $10 \mathrm{~min}$, and the supernatants were kept at $4{ }^{\circ} \mathrm{C}$ prior to use for peroxidase (POD) and superoxide dismutase (SOD) assays. Protein content was determined by the method of Lowry (Lowry et al. 1951), slightly modified by Peterson (1977), using bovine serum albumin as a standard.

Peroxidase activity was measured according to Pan et al. (2006) with minor modifications. The determination was based on the change of absorbance at $420 \mathrm{~nm}$ caused by decomposition of $\mathrm{H}_{2} \mathrm{O}_{2}$. One unit of POD activity (U) was defined as the amount of POD required to consume $1.0 \mu \mathrm{g}$ of the substrate by $1.0 \mathrm{mg}$ of the tissue protein in $1 \mathrm{~min}$ in the reaction system at $37^{\circ} \mathrm{C}$.

Superoxide dismutase activity was determined by the ferricytochrome- $c$ assay method using xanthine/xanthine oxidase as the source of superoxide radicals (McCord and Fridovich 1969). One unit SOD activity (U) was defined as the quantity of SOD required to produce a $50 \%$ inhibition of reduction of nitrite by $1.0 \mathrm{mg}$ tissue protein in $1.0 \mathrm{~cm}^{3}$ of a reaction solution by measuring the change of absorbance at $550 \mathrm{~nm}$.

The data were analyzed by one-way analysis of variance (ANOVA) using SPSS 19.0. Significant differences between data sets were tested by the least significant difference (LSD) test at $P<0.05$ and $P<0.01$.

Firstly, the effects of $\mathrm{Cd}$ and $\mathrm{Pb}$ stresses on the growth and proliferation of blueberry shoots in vitro were studied. Fig. $1 A$ showed that the height of blueberry shoots treated with $0.01 \mathrm{mM} \mathrm{Cd}^{2+}$ was significantly $(P<0.05)$ lower than that of the control, and the height gradually decreased with the increase of $\mathrm{Cd}^{2+}$ concentration. When the concentration of $\mathrm{Cd}^{2+}$ reached $0.05 \mathrm{~mm}$, the difference between the shoot height of the treatment and control was highly significant $(P<0.01)$. The height of the shoots after exposure to $1.00 \mathrm{mM} \mathrm{Cd}^{2+}$ decreased by $48 \%$. The effect of $\mathrm{Pb}^{2+}$ stress with the same concentration was different from that of $\mathrm{Cd}^{2+}$. There was no significant difference in shoot height between $0.01-1.00 \mathrm{mM} \mathrm{Pb}^{2+}$ treatment and control $(P>0.05)$.

The fresh mass of blueberry shoots decreased when $\mathrm{Cd}^{2+}$ was added to the medium. Already $0.01 \mathrm{mM} \mathrm{Cd}^{2+}$ could significantly $(P<0.01)$ decrease the fresh mass of the shoots, and the inhibitory effect was more obvious with the increase of the concentration of $\mathrm{Cd}^{2+}$. The fresh mass of the shoots after exposure to $1.00 \mathrm{mM} \mathrm{Cd}^{2+}$ was only $50 \%$ of the control (Fig. $1 B$ ). The ability of blueberry shoots to endure $\mathrm{Pb}^{2+}$ stress was stronger than $\mathrm{Cd}^{2+}$. Lower concentration of $\mathrm{Pb}^{2+}(\leq 0.50 \mathrm{mM})$ had no significant effect on the fresh mass of the shoots. The fresh mass of the shoots treated with $1.00 \mathrm{mM} \mathrm{Pb}^{2+}$ was significantly higher than that of the control $(P<0.05)$. Actually, $1.00 \mathrm{mM} \mathrm{Pb}^{2+}$ had no significant effect on the height of the shoots, but the shoots were stronger.

There was no significant difference in the proliferation coefficient of blueberry shoots after exposure to $0.01 \mathrm{mM}$ $\mathrm{Cd}^{2+}$ when compared with the control $(P>0.05)$, however, the proliferation ability decreased with the increase of $\mathrm{Cd}^{2+}$ concentration. After treatment with $\mathrm{Cd}^{2+}$ higher than $0.05 \mathrm{mM}$, the proliferation coefficient of the shoots was significantly lower than that of the control $(P<0.05)$, and there was highly significant difference $(P<0.01)$ between the shoots treated with $\mathrm{Cd}^{2+}$ higher than $0.10 \mathrm{mM}$ and the control. When $\mathrm{Cd}^{2+}$ concentration reached $1.00 \mathrm{mM}$, the proliferation coefficient was 1.00 , indicating that the proliferation ability of the shoots was stopped. The effect of $\mathrm{Pb}$ on the proliferation ability of blueberry shoots was less than that of $\mathrm{Cd}$. Although the proliferation coefficient after treatment of $\mathrm{Pb}^{2+}$ higher than $0.10 \mathrm{mM}$ was significantly lower than control $(P<0.01)$, there was no significant difference among $0.10-1.00 \mathrm{mM}$ $\mathrm{Pb}^{2+}$ treatments. When the concentration of $\mathrm{Pb}^{2+}$ reached $1.00 \mathrm{mM}$, blueberry shoots still had multiplication ability about 3 times (Fig. 1C).

Heavy metal pollution of soil has become a global environmental problem to be solved urgently (Ali et al. 2013, Wiafe et al. 2019). The tolerance and adaptability of plants to heavy metal pollution have been widely concerned by scientists and technologists. Under heavy metal stress, plants often show a series of physiological and metabolic changes such as growth inhibition (Chandrasekhar and Ray 2019, Murtaza et al. 2019, Xu et al. 2019), cell cycle progression inhibition (Hendrix et al. 2018) but increase in photosynthetic rate (Xu et al. 2019). Our results showed that the height and fresh mass of blueberry shoots decreased significantly after treatment of $\mathrm{Cd}^{2+}$ higher than $0.01 \mathrm{mM}$ (Fig. $1 A, B$ ), and the proliferation of the shoots was inhibited significantly after exposure to $\mathrm{Cd}^{2+}$ higher than $0.05 \mathrm{mM}$ (Fig. 1C). With the increase of $\mathrm{Cd}^{2+}$ concentration, the inhibition effect on the growth and proliferation of the shoots became more and more significant (Fig. $1 A-C$ ). When the concentration of $\mathrm{Pb}^{2+}$ reached $0.10 \mathrm{mM}$, the proliferation of blueberry shoots was significantly affected, however, the inhibition was less than that of the same concentration of $\mathrm{Cd}^{2+}$ (Fig. 1C). Lead at concentration $0.01-1.00 \mathrm{mM}$ did not significantly decrease the height and fresh mass of the shoots (Fig. $1 A, B$ ), suggesting that the effect of $\mathrm{Pb}^{2+}$ on the growth of the shoots was less than the effect on the proliferation capacity. Our results and previous results from Salix (Xu et al. 2019) and wheat (Murtaza et al. 2019) indicate that the toxicity of $\mathrm{Cd}^{2+}$ to plants is greater than $\mathrm{Pb}^{2+}$, and the tolerance threshold of plants to $\mathrm{Pb}$ is higher than $\mathrm{Cd}$, that is to say, the tolerance of plants to lead is stronger than to cadmium. Probably $\mathrm{Pb}$ might be 


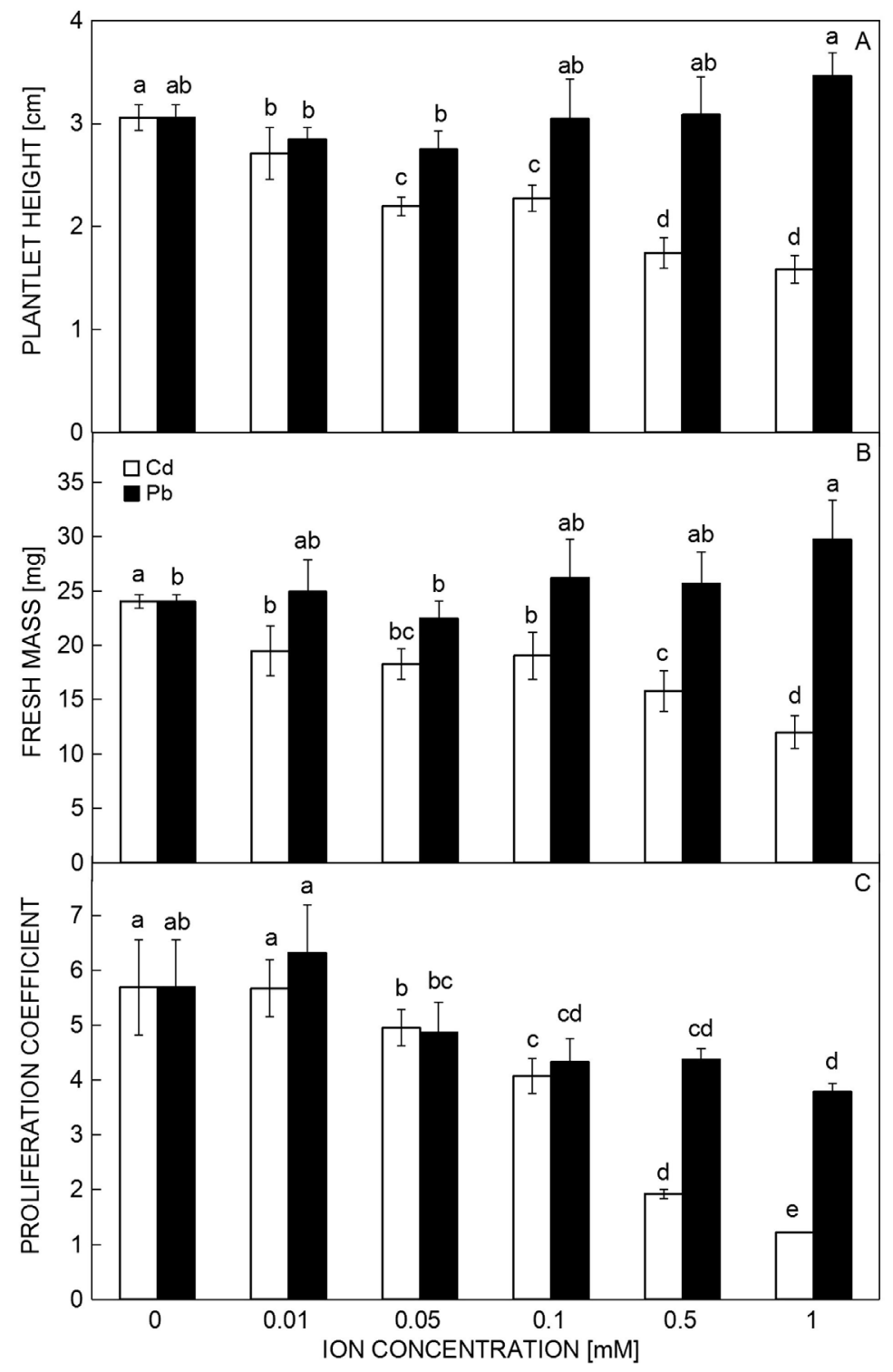

Fig. 1. The effect of $\mathrm{Cd}$ and $\mathrm{Pb}$ stress on height $(A)$, fresh mass $(B)$, and proliferation $(C)$ of blueberry shoots. Means $\pm \mathrm{SEs}$, $n=3$; different letters indicate significant differences at $P<0.05$.

used as a "trace element" in blueberry culture medium, as low concentration of $\mathrm{Pb}$ might be beneficial to the growth of blueberry shoots.

Heavy metal stresses in plants have been documented from the aspects of physiology, biochemistry (RomeroPuertas et al. 2019), genetics (Zorrig et al. 2019), and molecular biology (Akbudak and Filiz 2019, Zhang et al. 2020). In the present study, the activities of POD and SOD in blueberry shoots after exposure to $\mathrm{Cd}$ and $\mathrm{Pb}$ were investigated. After $10 \mathrm{~d}$ of treatment with $\mathrm{Cd}^{2+}$ or $\mathrm{Pb}^{2+}$, the POD activity of blueberry shoots showed an increasing trend with the increase of their concentration (Fig. 2A). When $\mathrm{Cd}^{2+}$ concentration was $1.00 \mathrm{mM}$, POD activity was significantly $(P<0.05)$ higher than in control, while POD activity of the shoots was significantly higher than in control $(P<0.05)$ when the concentration of $\mathrm{Pb}^{2+}$ was higher than $0.01 \mathrm{mM}$, and there was highly significant increase $(P<0.01)$ after treatment with $\mathrm{Pb}^{2+}$ higher than $0.10 \mathrm{mM}$ (Fig. $2 A$ ). After $20 \mathrm{~d}$ of exposure the POD activity of blueberry shoots also increased with the increase of the concentration of $\mathrm{Cd}$ or $\mathrm{Pb}$ (Fig. $2 B$ ). POD activity after 20-d exposure to $0.10 \mathrm{mM} \mathrm{Cd}^{2+}$ was significantly higher than in the control $(P<0.05)$, and there was highly significant difference $(P<0.01)$ between $1.00 \mathrm{mM} \mathrm{Cd}^{2+}$ and the control. The POD activity of the shoots after 20- $\mathrm{d}$ exposure to $0.01 \mathrm{mM} \mathrm{Pb}^{2+}$ was significantly higher than in the control $(P<0.05)$, and the difference between $1.00 \mathrm{mM} \mathrm{Pb}{ }^{2+}$ and the control was highly significant $(P<0.01)$ (Fig. 2B).

After $10 \mathrm{~d}$ of culture, $0.01-1.00 \mathrm{mM} \mathrm{Cd}$ had no significant effect on SOD activity of blueberry shoots (Fig. 2C). The SOD activity of the shoots treated with $1.00 \mathrm{mM} \mathrm{Pb}^{2+}$ was significantly higher than that of the control $(P<0.05)$, while other concentrations of $\mathrm{Pb}^{2+}$ had 


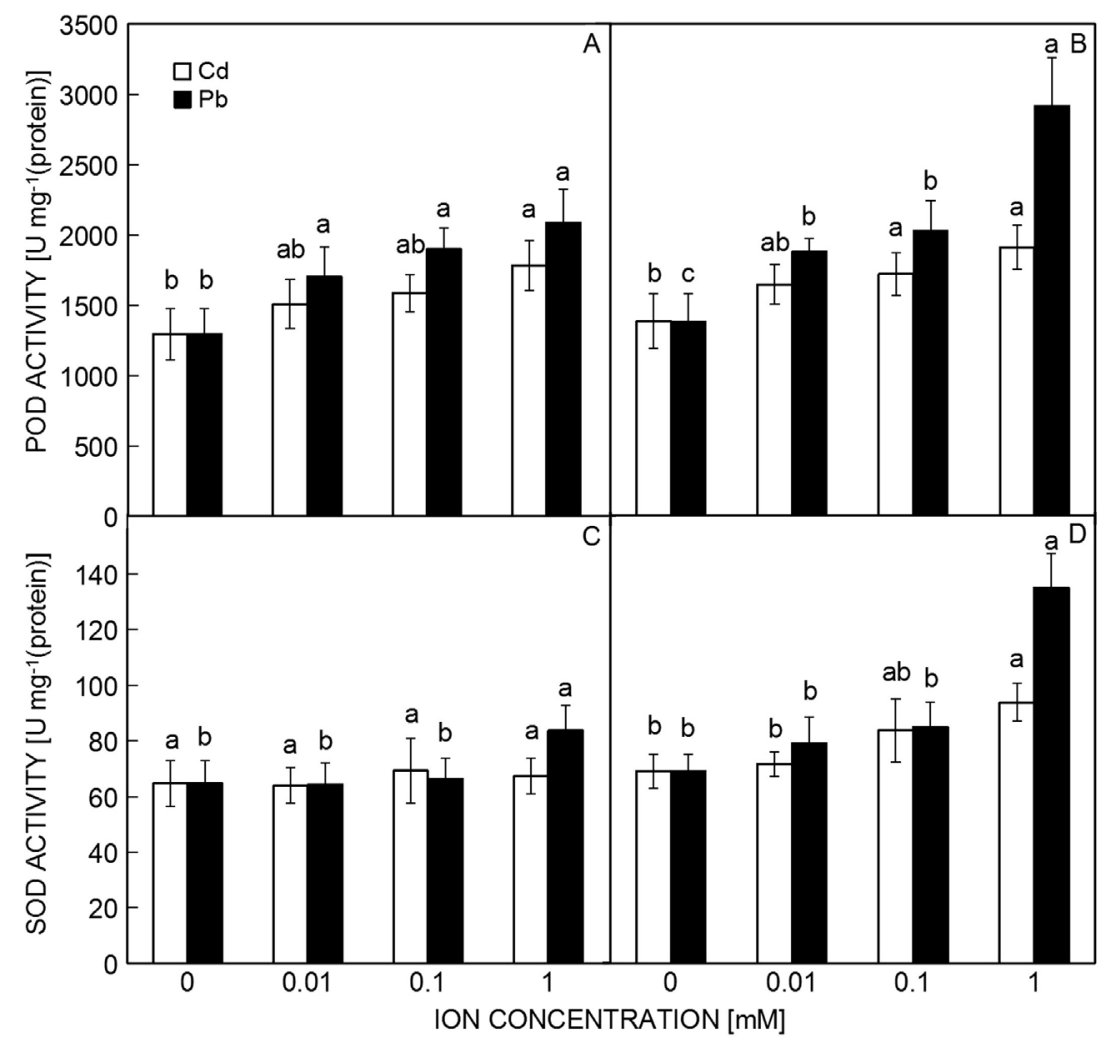

Fig. 2. The effect of $\mathrm{Cd}$ and $\mathrm{Pb}$ stress on peroxidase (POD) activity after $10 \mathrm{~d}(A)$ and $20 \mathrm{~d}(B)$, and superoxide dismutase (SOD) activity after $10 \mathrm{~d}(C)$ and $20 \mathrm{~d}(D)$ of exposure in blueberry shoots. Means \pm SEs, $n=3$; different letters indicate significant differences at $P<0.05$.

no significant effect on SOD activity (Fig. 2C). After $20 \mathrm{~d}$ of treatment, the $\mathrm{SOD}$ activity under $\mathrm{Cd}$ or $\mathrm{Pb}$ stresses increased with the increase of their concentrations. The SOD activity of the shoots treated with $1.00 \mathrm{mM} \mathrm{Cd}^{2+}$ or $\mathrm{Pb}^{2+}$ was significantly higher than that of the control $(P<0.01)$, however, there was no significant difference between the other treatments and the control (Fig. 2D).

It is well known that ROS steady-state content is regulated by the interplay between different ROSproducing and ROS-scavenging mechanisms (RomeroPuertas et al. 2019). ROS production is a common feature in plants under heavy metal stress (Pellegrini et al. 2019). $\mathrm{Pb}$ and $\mathrm{Cd}$, as nonredox heavy metals, can cause overproduction of ROS indirectly through the inhibition of antioxidative defense system or by stimulation of membrane bound NADPH oxidases (Pandey and Singh 2012, Chmielowskabąk et al. 2014). The ROS-scavenging mechanism involves enzymatic antioxidants such as superoxide dismutase (SOD), peroxidase (POD) and catalase (CAT), and non-enzymatic compounds such as glutathione (GSH) and proline (Halliwell and Gutteridge 2015, Romero-Puertas et al. 2019). The present study demonstrated that the activity of POD and SOD of the shoots mostly increased when blueberry plants were exposed to $\mathrm{Cd}$ or $\mathrm{Pb}$ stress, except for the $\mathrm{SOD}$ activity after $10 \mathrm{~d}$ of exposure (Fig. 2). These results suggest that the increase in the activities of POD and SOD in blueberry shoots, and so ROS scavenging could improve their $\mathrm{Pb}$ and $\mathrm{Cd}$ tolerance. Fig. 2 also showed that the effect of $\mathrm{Pb}$ on POD and SOD activities was stronger than that of $\mathrm{Cd}$; this result explains why the inhibitory effect of $\mathrm{Pb}$ on the growth and proliferation of blueberry was lower than that of the same concentration of Cd (Fig. 1).

Recently, the effects of cadmium and lead on the growth and development of plants have been well documented (Murtaza et al. 2019, Xu et al. 2019), however, most studies on heavy metal stress of plants had not been carried out under sterile culture conditions. Therefore, the previous results were inevitably affected by the role of microorganisms because some studies have shown that some bacteria can not only absorb heavy metals such as cadmium and lead, but also can fix them (Bravo et al. 2018, Pakdel et al. 2019). Our experiment was performed under completely aseptic culture condition, which excluded the influence of microorganisms on $\mathrm{Cd}^{2+}$ and $\mathrm{Pb}^{2+}$, and truly reflected the influence of $\mathrm{Cd}$ and $\mathrm{Pb}$ stress on the growth of blueberry plantlets. It can provide a useful reference for the same kind of related research.

In conclusion, $\mathrm{Cd}$ stress significantly inhibited the growth and proliferation of blueberry shoots, whereas $\mathrm{Pb}$ stress only significantly restrained the shoot proliferation. The activities of POD and SOD in the shoots after exposure to $\mathrm{Cd}$ or $\mathrm{Pb}$ increased to mitigate the ROS accumulation caused by heavy metals. The results suggest that blueberry shoots exhibit higher tolerance to $\mathrm{Pb}$ than to $\mathrm{Cd}$. 


\section{References}

Akbudak, M.A., Filiz, E.: Genome-wide analyses of ATP sulfurylase (ATPS) genes in higher plants and expression profiles in sorghum (Sorghum bicolor) under cadmium and salinity stresses. - Genomics 111: 579-589, 2019.

Ali, H., Khan, E., Sajad, M.A.: Phytoremediation of heavy metals: concepts and applications. - Chemosphere 91: 869881,2013

Bravo, D., Pardo-Díaz, S., Benavides-Erazo, J., Rengifo-Estrada, G., Braissant, O., Leon-Moreno, C.: Cadmium and cadmiumtolerant soil bacteria in cacao crops from northeastern Colombia. - J. appl. Microbiol. 124: 1175-1194, 2018.

Chandrasekhar, C., Ray, J.G.: Lead accumulation, growth responses and biochemical changes of three plant species exposed to soil amended with different concentrations of lead nitrate. - Ecotoxicol. Environ. Safety 171: 26-36, 2019.

Chen, L., Luo, S.L., Li, X.J., Wan, Y., Chen, J.L., Liu, C.B.: Interaction of Cd-hyperaccumulator Solanum nigrum L. and functional endophyte Pseudomonas sp. Lk9 on soil heavy metals uptake. - Soil Biol. Biochem. 68: 300-308, 2014.

Chmielowskabąk, J., Gzyl, J., Rucińskasobkowiak, R., Arasimowiczjelonek, M., Deckert, J. The new insights into cadmium sensing. - Front. Plant Sci. 5: 245, 2014.

Halliwell, B., Gutteridge, J.M.C.: Free Radicals in Biology and Medicine (Fifth Edition). - Oxford University Press, Oxford 2015.

Hendrix, S., Keunen, E., Mertens, A.I.G., Beemster, G.T.S., Vangronsveld, J., Cuypers, A.: Cell cycle regulation in different leaves of Arabidopsis thaliana plants grown under control and cadmium-exposed conditions. - Environ. exp. Bot. 155: 441-452, 2018.

Kalt, W., Joseph, J.A., Shukitt-Hale, B.: Blueberries and human health: a review of current research. - J. amer. pomol. Soc. 61: 151-160, 2007.

Kalt, W., Cassidy, A., Howard, L.R., Krikorian, R., Stull, A.J., Tremblay, F., Zamora-Ros, R.: Recent research on the health benefits of blueberries and their anthocyanins. - Adv. Nutr. 11: 224-236, 2020

Lloyd, G., McCown, B.: Commercially feasible micropropagation of mountain laurel, Kalmia latifolia, by use of shoot tip culture. - Proc. Int. Plant Propag. Soc. 30: 421-427, 1980.

Lowry, O.H., Rosebrough, N.H., Farr, A.L., Randall, R.J.: Protein measurement with the Folin phenol reagent. - J. biol. Chem. 193: 265-275, 1951.

Markus, J.A., Mcbratney, A.B.: An urban soil study-heavy metals in Glebe, Australia. - Aust. J. Soil Res. 34: 453-465, 1996.

McCord, J.M., Fridovich, I.: Superoxide dismutase. An enzymic function for erythrocuprein (hemocuprein). - J. biol. Chem. 244: 6049-6055, 1969

Murtaza, B., Naeem, F., Shahid, M., Abbas, G., Shah, N.S., Amjad, M., Bakhat, H.F., Imran, M., Niazi, N.K., Murtaza, G.: A multivariate analysis of physiological and antioxidant responses and health hazards of wheat under cadmium and lead stress. - Environ. Sci. Pollut. Res. 26: 362-370, 2019.

Pakdel, M., Soleimanian-Zad, S., Akbari-Alavijeh, S.: Screening of lactic acid bacteria to detect potent biosorbents of lead and cadmium. - Food Control 100: 144-150, 2019.

Pan, Y., Wu, L.J, Yu, Z.L.: Effect of salt and drought stress on antioxidant enzymes activities and SOD isoenzymes of liquorice (Glycyrrhiza uralensis Fisch). - Plant Growth Regul. 49: $157-165,2006$.

Pandey, N., Singh, G.K.: Studies on antioxidative enzymes induced by cadmium in pea plants (Pisum sativum). - J. environ. Biol. 33: 201-206, 2012.

Pellegrini, E., Hoshika, Y., Dusart, N., Cotrozzi, L., GéRard, J., Nali, C., Paoletti, E.: Antioxidative responses of three oak species under ozone and water stress conditions. - Sci. total Environ. 647: 390-399, 2019.

Peterson, G.L.: A simplification of the protein assay method of Lowry et al. which is more generally applicable. - Anal. Biochem. 83: 570-577, 1977.

Romero-Puertas, M.C., Terrón-Camero, L.C., Peláez-Vico, M.Á., Olmedilla, A., Sandalio, L.M.: Reactive oxygen and nitrogen species as key indicators of plant responses to $\mathrm{Cd}$ stress. - Environ. exp. Bot. 161: 107-119, 2019.

Strik, B.: Blueberry: An expanding world berry crop. - Chronica Hort. 45: 7-12, 2005.

Strik, B.C., Yarborough, D.: Blueberry production trends in North America, 1992 to 2003, and predictions for growth. HortTechnology 15: 391-398, 2005.

Tóth, G., Hermann, T., Da Silva, M.R., Montanarella, L.: Heavy metals in agricultural soils of the European Union with implications for food safety. - Environ. Int. 88: 299-309, 2016.

Wiafe, S., Buamah, R., Essandoh, H., Darkwah, L.: Assessment of Typha capensis for the remediation of soil contaminated with $\mathrm{As}, \mathrm{Hg}, \mathrm{Cd}$ and $\mathrm{Pb}$. - Environ. Monit. Assess. 191: 1-14, 2019.

Xiao, Q., Zong, Y.T., Lu, S.G.: Assessment of heavy metal pollution and human health risk in urban soils of steel industrial city (Anshan), Liaoning, northeast China. Ecotoxicol. Environ. Safety 120: 377-385, 2015.

Xu, X.H., Yang, B.S., Qin, G.H., Wang, H., Zhu, Y.D., Zhang, K.Z., Yang, H.Q.: Growth, accumulation, and antioxidative responses of two Salix genotypes exposed to cadmium and lead in hydroponic culture. - Environ. Sci. Pollut. Res. 26: 19770-19784, 2019.

Zhang, F.G., Xiao, X., Xu, K., Cheng, X., Xie, T., Hu, J.H., $\mathrm{Wu}$, X.M.: Genome-wide association study (GWAS) reveals genetic loci of lead $(\mathrm{Pb})$ tolerance during seedling establishment in rapeseed (Brassica napus L.). - BMC Genomics 21: 139-150, 2020.

Zorrig, W., Cornu, J.Y., Maisonneuve, B., Rouached, A., Sarrobert, C., Shahzad, Z., Abdelly, C., Davidian, J.C., Berthomieu, P.: Genetic analysis of cadmium accumulation in lettuce (Lactuca sativa). - Plant Physiol. Biochem. 136: 67 75, 2019. 